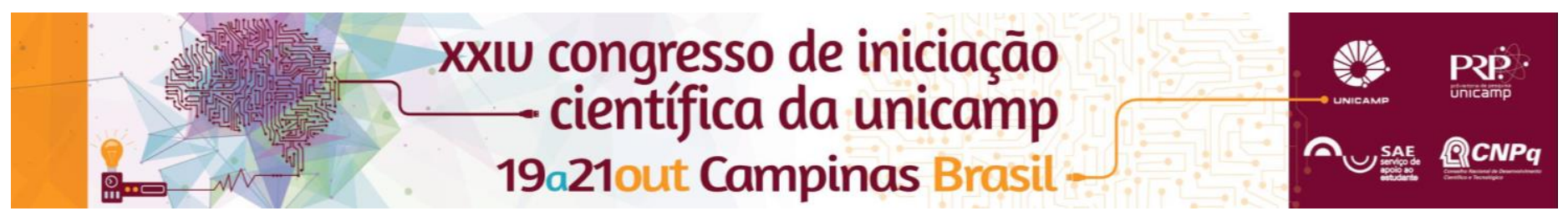

\title{
Avaliação da atividade antimicrobiana do óleo essencial de Mentha piperita
}

\author{
PASCHOALINI, L. V.*; SILVA, A.H.Z.M.; SILVA, M.R.B.; HOFLING, J.F.
}

\section{Resumo}

Mentha spp. são conhecidas pelo seu potencial medicinal e têm demonstrado atividade antimicrobiana em estudos encontrados na literatura. O presente trabalho objetivou avaliar a atividade antibacteriana do óleo essencial de Mentha piperita em busca da CIM (concentração inibitória mínima), através do teste de microdiluição em caldo. O óleo essencial de Mentha piperita se mostrou eficaz na inibição das bactérias testadas, com exceção de $S$. gordonii.

\section{Palavras-chave}

Mentha spp., Plantas medicinais e Atividade antibacteriana

\section{Introdução}

As plantas medicinais há muito vêm sendo empregadas como terapêutica no tratamento de doenças, utilizando seus extratos, óleos e respectivos componentes bioativos. Nesse contexto, Mentha spp., conhecida popularmente como hortelã, é uma das plantas mais citadas em estudos etnofarmacológicos e microbiológicos. Os resultados desses estudos, associado ao aumento de casos de resistência à antimicrobianos apresentadas por alguns microrganismos, evidencia a importância de trabalhos que visam a busca de novas alternativas de compostos antimicrobianos.

O trabalho teve por objetivo avaliar a atividade antibacteriana do óleo essencial de Mentha piperita em busca da CIM (concentração inibitória mínima).

\section{Resultados e Discussão}

A concentração inibitória mínima $(\mathrm{CIM})$ do óleo essencial testado foi determinada pelo teste de susceptibilidade à antimicrobianos por microdiluição em caldo, e foi analisada por leitura visual do crescimento microbiano após incubação de 24 horas.

O óleo essencial de Mentha piperita mostrou efeito inibitório de crescimento dos microrganismos em $S$. aureus, E. coli, S. epidermidis e $S$. mitis $(4 \mathrm{mg} / \mathrm{ml})$, sendo mais eficiente na inibição de $P$. aeruginosa, $S$. mutans, S. salivarius e Salmonella sp. $(2 \mathrm{mg} / \mathrm{ml})$.

\section{Conclusões}

Com exceção de S. gordonii, o óleo essencial de Mentha piperita se mostrou eficaz na inibição de crescimento em testes in vitro contra as bactérias testadas, sendo mais eficiente no controle do crescimento de Salmonella sp., P.aeruginosa, S. mutans e S. salivarius.

\section{Agradecimentos}

\section{FAEPEX, FUNCAMP e CNPq} . 